\title{
Detecção do Southern bean mosaic virus no Paraná, e Separação do Bean rugose mosaic virus em Feijoeiro
}

\author{
Marcos D. G. Gasparin ${ }^{1}$, Anésio Bianchini ${ }^{2}$, Eliezer R. de Souto ${ }^{1}$, José Osmar Gaspar ${ }^{3}$ Álvaro M. R. \\ Almeida $^{4}$ \& Elliot W. Kitajima ${ }^{5}$
}

${ }^{1}$ Universidade Estadual de Maringá, CCA- DAG, Av. Colombo, 5790, CEP 87020-900, Maringá, PR; e-mail: ersouto@uem.br, ${ }^{2}$ Instituto Agronômico do Paraná, IAPAR, Cx. Postal 481, CEP 86001-970, Londrina, PR, ${ }^{3}$ IBILCE/ UNESP, CEP 15054-000, São José do Rio Preto, SP, ${ }^{4}$ Embrapa Soja, Cx. Postal 231, CEP 86001-970, Londrina, PR, ${ }^{5}$ NAP/MEPA, ESALQ/USP, Piracicaba, SP, CEP 13480-000

(Aceito para publicação em 16/09/2004)

Autor para correspondência: Eliezer Rodrigues de Souto

GASPARIN, M.D.G., BIANCHINI, A., SOUTO, E.R., GASPAR, J.O., ALMEIDA, A.M.R. \& KITAJIMA, E.W. Detecção do Southern bean mosaic virus no Paraná e separação do Bean rugose mosaic virus em feijoeiro. Fitopatologia Brasileira 30:7578. 2005.

\section{RESUMO}

Em lavouras de feijoeiro (Phaseolus vulgaris) da cultivar Carioca Comum, no município de Londrina, Estado do Paraná, foram encontradas plantas com sintomas de necrose da haste, mosaico clorótico leve e porte reduzido, semelhantes aos sintomas causados por infecção viral. Exames de microscopia eletrônica revelaram a presença de partículas isométricas. Em testes de imunodifusão dupla em gel de ágar os extratos foliares de plantas infetadas reagiram positivamente com anti-soro específico para o Southern bean mosaic virus (SBMV). O vírus foi purificado e a massa molecular de sua proteína capsidial foi estimada em 30 $\mathrm{kDa}$, valor esperado para proteínas do capsídeo de vírus do gênero Sobemovirus. A gama de hospedeiras do SBMV isolado no Paraná foi restrita ao feijoeiro e a algumas cultivares de soja (Glycine max). A separação de dois vírus isométricos comuns em infecções mistas no feijoeiro foi possível através da reação de imunidade ao SBMV apresentada por Crotalaria sp, Chenopodium quinoa e Mucuna deeringiana, e da reação de susceptibilidade dessas mesmas hospedeiras ao Bean rugose mosaic virus (BRMV).

Palavras-chave adicionais: SBMV, Sobemovirus, BRMV.

\begin{abstract}
Detection of Southern bean mosaic virus in the State of Paraná and separation from Bean rugose mosaic virus in bean Plants of bean (Phaseolus vulgaris), showing symptoms of stunt, stem necrosis and chlorotic mosaic, similar to those induced by virus infection were found in a bean field in Londrina, Paraná. Electron microscopy examinations showed isometric virus particles in the cell cytoplasm. Double immunodifusion serological tests with antiserum for Southern bean mosaic virus (SBMV) gave positive results when tested against plant sap from infected bean plants. The virus was purified and the molecular mass of its coat protein was estimated as $30 \mathrm{kDa}$, the expected value for the coat protein of viruses from the genus Sobemovirus. The host range of the virus was restricted to bean and some soybean (Glycine max) cultivars. It was possible to separate two isometric viruses commonly found in bean based on the immunity reaction of Crotalaria sp., Chenopodium quinoa and Mucuna deeringiana to SBMV, and on the susceptibility reaction of the same hosts to Bean rugose mosaic virus (BRMV).
\end{abstract}

Additional keywords: SBMV, Sobemovirus, BRMV.

A produção mundial de feijão (Phaseolus vulgaris L.) é da ordem de 18,9 milhões de toneladas. O Brasil é o maior produtor (3-4 milhões de toneladas), superado apenas pela Índia (FAO, 2004). A produtividade da cultura é grandemente afetada por doenças, e aquelas causadas por vírus representam um dos principais fatores associados às perdas na América Latina e no Brasil, tanto pela redução da produtividade e qualidade, quanto pela dificuldade de seu controle (Gálvez \& Cardeñas, 1980; Costa, 1987).

No Brasil, foram descritas mais de dez viroses em feijoeiro (Bianchini et al., 1997). Um dos problemas clássicos é

\footnotetext{
*Parte da Dissertação de Mestrado do primeiro autor. Universidade Estadual de Maringá (2002).
}

o mosaico comum, causado pelo Bean common mosaic virus (BCMV) pertencente à família Potyviridae, gênero Potyvirus, podendo causar perdas de 35 a $98 \%$ da produção, dependendo do estádio da planta na época da infecção (Faria et al., 1996). O mosaico dourado é a virose mais importante, causada pelo Bean golden mosaic virus (BGMV), família Geminiviridae, gênero Begomovirus. No Estado do Paraná têm sido observadas infecções simples do BGMV, ou infecções mistas, tanto com espécies de outros geminivirus, como com vírus isométricos, destacando-se o Bean rugose mosaic virus (BRMV) família Comoviridae, gênero Comovirus. As infecções mistas ocorrem principalmente na safra da seca, quando se observa maior incidência do BGMV. Os danos provocados nestes casos são 
M.D.G. Gasparin et al.

mais severos que aqueles causados pelas infecções individuais por qualquer um dos vírus. Um outro fator agravante é que nas cultivares com resistência ao BGMV, a mesma é perdida quando ocorre a infecção mista do BGMV com vírus isométricos de outros gêneros (Bianchini et al., 1997).

No Brasil, o Southern bean mosaic virus (SBMV), gênero Sobemovirus, primeiramente foi relatado infetando feijoeiro no Distrito Federal, ocasionando sintomas de mosaico fraco a severo, deformação da vagem e distorção foliar (Cupertino et al., 1982). Posteriormente foi encontrado no Estado de São Paulo (Costa, 1987), tendo sido este isolado parcialmente caracterizado ao nível molecular (Moreira \& Gaspar, 2002).

No presente trabalho, são apresentadas as propriedades biológicas de um isolado paranaense do SBMV e as hospedeiras diferenciadoras para a sua separação do BRMV, os quais são vírus isométricos comumente associados às infecções mistas em feijoeiro.

O isolado de SBMV utilizado neste trabalho foi obtido de plantas de feijoeiro 'Carioca Comum', com sintomas de deformação de folhas e necrose sistêmica, a partir de amostras de feijoeiros procedentes de lavouras do município de Londrina. $\mathrm{O}$ isolado de BRMV foi também obtido de plantas de feijoeiro provenientes de uma região produtora do sudoeste do Paraná, e foi identificado com base nos sintomas induzidos em variedades de feijoeiro, na gama de hospedeiras diferenciadoras citadas neste trabalho, e na morfologia das partículas. Para manutenção, os isolados virais foram perpetuados em plantas de feijoeiro 'Rosinha-G2' e 'Carioca Comum', por meio de inoculação mecânica.

Folhas primárias de plantas das famílias Amaranthaceae, Chenopodiaceae, Cucurbitaceae, Solanaceae e Leguminosae foram inoculadas mecanicamente. $\mathrm{O}$ inóculo foi obtido por maceração de folhas de feijoeiro infetadas em tampão fosfato pH 7,0,0,02M, na proporção de $1: 1(\mathrm{p} / \mathrm{v})$, contendo $0,1 \%$ de sulfito de sódio, sendo as plantas inoculadas mantidas em casa de vegetação. As avaliações foram realizadas através da observação da reação apresentada, tendo sido efetuadas três avaliações entre 12 e 50 dias após a inoculação.

Plantas de feijoeiro 'Rosinha-G2', 'Carioca Comum', 'Jalo', 'Carnaval', 'Bolinha', 'Moro' e 'Olho de Pomba' e soja [Glycine $\max$ (L.) Merril] 'Santa Rosa' foram inoculadas mecanicamente com o SBMV. Ao final do ciclo foram coletadas 100 sementes de cada cultivar infetada para se avaliar a transmissão. As sementes foram semeadas em vasos mantidos em casa de vegetação.

Besouros [Diabrotica sp.eciosa Germ. (Coleoptera, Chrysomelidae)] coletados de plantas de tomate (Lycopersicon esculentum Mill.) foram mantidos em feijoeiro 'Rio Tibagi' sadio, em gaiolas por aproximadamente cinco dias. Após este período, os insetos foram transferidos para plantas de feijoeiro 'Carioca Comum' infetadas com o vírus, onde foram mantidos por $48 \mathrm{~h}$. Em seguida, foram transferidos para feijoeiro 'Carioca Comum' sadio colocando-se dez insetos por planta. Foram utilizadas quatro plantas em cada um dos três ensaios realizados em gaiolas insetárias de tela antiafídica.
$\mathrm{Na}$ transmissão por enxertia, do tipo garfagem, foram usadas como enxerto pontas de ramos ou brotos de feijoeiro 'Carioca Comum' com sintomas de lesões necróticas e encarquilhamento e, como porta-enxerto, cinco plantas sadias de feijão caupi (Vigna unguiculata L.) de cada uma das doze linhagens testadas, TE93-213-12F-1, TE93-213-12F-2, TE93-21411F, TE94-256-6E, TE94-268-3E, TE94-270-4E, TE90-180-88E, Paulista, IPA-206, EPACE-10, BR17-Gurguéia, e EVx41-5E. Todas as plantas foram mantidas em casa de vegetação e avaliadas por um período de até 35 dias após a enxertia para se verificar a possível manifestação de sintomas nos portaenxertos.

Amostras de folhas de feijeoiro 'Carioca Comum' com sintomas de encarquilhamento severo e necrose sistêmica nas nervuras foram utilizadas para exames ao microscópio eletrônico conforme o método descrito por Kitajima \& Nome (1999).

Foram realizados testes de imunodifusão dupla, em placas de Petri, em meio de ágar Noble Difco $0,75 \%(\mathrm{p} / \mathrm{v}), \mathrm{NaCl}$ $0,85 \%(\mathrm{p} / \mathrm{v})$ e $0,02 \%(\mathrm{p} / \mathrm{v})$ de azida sódica $\left(\mathrm{NaN}_{3}\right)$. Foram utilizados anti-soros específicos para o SBMV e para o Southern cowpea mosaic virus (SCPMV), Sobemovirus, gentilmente cedidos pelo Dr. Hiebert (University of Florida, Gainesville, USA). Como antígenos foram utilizados extratos obtidos de folhas de feijoeiro e de soja infetadas pelo SBMV e extratos de folhas de feijão 'Rosinha-G2' infetadas com o BCMV.

O SBMV foi purificado utilizando um método adaptado do protocolo descrito por Hull (1977). A partir da trituração de folhas infetadas, congeladas ou frescas, de feijoeiro 'Carioca Comum', o vírus foi extraído com tampão $\mathrm{KH}_{2} \mathrm{PO}_{4}(0,1 \mathrm{M}$, pH $7,2)$, na proporção de $1: 2(\mathrm{p} / \mathrm{v})$, clarificado com clorofórmio $(0,5$ $\mathrm{ml} / \mathrm{g}$ de folha) e precipitado com PEG $8000(10 \%$, p/v), na presença de $\mathrm{NaCl}(1 \%, \mathrm{p} / \mathrm{v})$. Em seguida, foram realizados um ciclo de baixa e alta rotações $(16.000 \mathrm{~g} / 10 \mathrm{~min}$ e $100.000 \mathrm{~g} / 90$ min) e um gradiente linear de sacarose (10-50\%) em tampão $\mathrm{KH}_{2} \mathrm{PO}_{4}(0,01 \mathrm{M}, \mathrm{pH} 7,2)$. A banda contendo o vírus foi diluída no tampão mencionado anteriormente e centrifugada por 90 min a $100.000 \mathrm{~g}$. Recuperou-se o sedimento em $1 \mathrm{ml}$ de tampão e analisou-se em espectrofotômetro.

A determinação da massa molecular da proteína capsidial do vírus foi realizada através de eletroforese em gel de poliacrilamida com SDS (SDS-PAGE) a 12,5\%, segundo o método de Laemmli (1970) com modificações para gel contínuo. Para o preparo da amostra utilizou-se $30 \mu \mathrm{l}$ do vírus purificado, $10 \mu \mathrm{l}$ de SDS $10 \%$ (p/v) e $3 \mu \mathrm{l}$ de â-mercaptoetanol, aquecendose a mistura a $100^{\circ} \mathrm{C}$ durante $3 \mathrm{~min}$.

Inicialmente, levantou-se a possibilidade de que os sintomas de lesões necróticas observados em feijoeiro 'Carioca Comum' cultivados no Paraná poderiam estar associados a uma infecção natural causada por vírus do gênero Potyvirus, os quais podem causar sintomas necróticos, dependendo da temperatura ambiente. Tal hipótese foi eliminada através de exames por microscopia eletrônica, que indicaram a presença de partículas virais isométricas dispersas no citoplasma. Em testes de imunodifusão dupla em gel de ágar utilizando antisoros para o SBMV e para o SCPMV, os extratos de folhas de feijoeiro infetadas reagiram com o anti-soro para SBMV (Figura 
1) e não reagiram com o anti-soro para o SCPMV, indicando que o isolado em questão é o SBMV. A determinação da massa molecular da proteína do capsídeo em $30 \mathrm{KDa}$, valor esperado para vírus do gênero Sobemovirus, reforçou a identificação do vírus (Figura 2). No entanto, a transmissão por Diabrotica speciosa deste isolado viral não foi verificada nos testes realizados. Este resultado diverge do obtido por Costa et al. (1987), que relataram em campo experimental a transmissão de um Sobemovirus por D. speciosa e Cerotoma arcuata (Oliv.) (Col. Chrysomelidae). Não se verificou a transmissão mecânica e nem por enxertia para as linhagens de caupi testadas, indicando se tratar da estirpe B do SBMV, pois esta não infeta caupi (Tremaine \& Hamilton, 1983). Quanto à gama de hospedeiras, somente espécies pertencentes à família Leguminosae foram infetadas com o isolado paranaense do SBMV. Essas espécies foram restritas a algumas cultivares de feijão e de soja (Tabela 1). A ausência de transmissão para as outras leguminosas testadas assemelha-se aos resultados obtidos por Cupertino et al. (1982) e Costa et al. (1987), os quais afirmaram que as cultivares de feijoeiro Carioca e Rosinha são hospedeiras sintomáticas do SBMV e a cultivar Rio Tibagi é hospedeira assintomática. A gama de hospedeiras indica que o isolado de SBMV seja da estirpe B, pois de acordo com Tremaine \& Hamilton (1983), a estirpe B (Bean strain) infeta diversas cultivares de feijoeiro comum e não infeta caupi, e a estirpe C (Cowpea strain) infeta caupi, mas não infeta o feijoeiro comum, com exceção das cultivares Pinto. As estirpes G (Ghana strain) e M (Mexican strain) infetam ambas as espécies. As estirpes B e C do SBMV são reconhecidas atualmente como espécies distintas do gênero Sobemovirus, sendo denominadas SBMV e SCPMV, respectivamente (Fauquet \& Mayo, 1999).

A imunidade de C. quinoa ao SBMV, utilizado neste trabalho, constitui-se em um fator importante para a sua separação do BRMV. Conforme Cupertino et al. (1982), na diagnose e isolamento do BRMV quando em infecção mista com o SBMV em feijoeiro, somente o BRMV induziu o

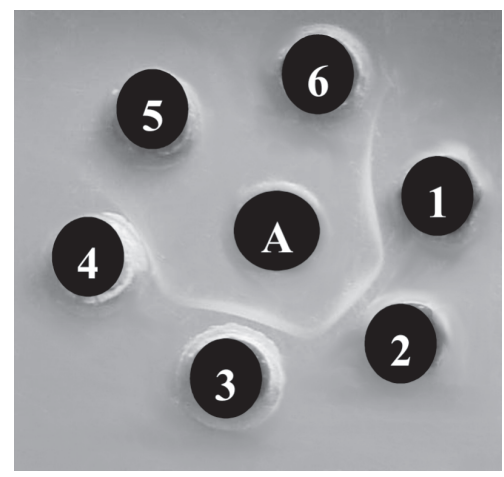

FIG. 1 - Teste de imunodifusão dupla em gel de ágar: (A) anti-soro para o Southern bean mosaic virus (SBMV); $(1,2,3,4)$ extrato de folha de feijoeiro (Phaseolus vulgaris) 'Carnaval', 'Carioca Comum', 'Bolinha' e 'Rosinha-G2', respectivamente, infetadas com o SBMV, (5) extrato de folha de feijoeiro 'Rosinha-G2' infetado com o Bean common mosaic virus (BCMV); (6) extrato de folha de feijoeiro 'Carioca Comum' sadio.

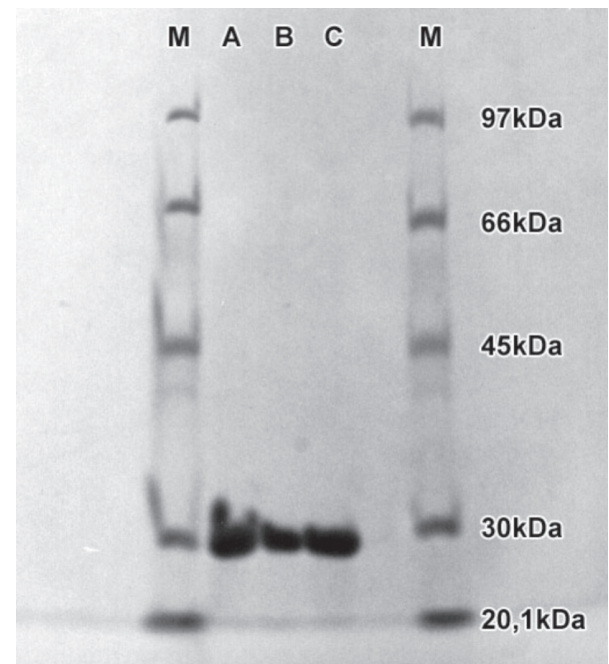

FIG. 2 - Perfil eletroforético da proteína capsidial do Southern bean mosaic virus (SBMV) isolado no Paraná, em gel de poliacrilamida a $12,5 \%$ : A, B e C amostras do vírus purificado. $\mathrm{M}$, marcadores moleculares $(97 \mathrm{KDa}$ - fosforilase, $66 \mathrm{KDa}$ - albumina de soro bovino, $45 \mathrm{KDa}$-ovoalbumina, $30 \mathrm{KDa}$ - anidrase carbônica, e 20,1 KDa-inibidor de tripsina).

TABELA 1 - Comparação da reação induzida pelo Southern bean mosaic virus (SBMV) e Bean rugose mosaic virus (BRMV) em algumas espécies e cultivares diferenciadoras

\begin{tabular}{|c|c|c|c|c|}
\hline \multirow{3}{*}{ Espécie/cultivar } & \multirow{2}{*}{\multicolumn{2}{|c|}{$\begin{array}{c}\text { SBMV } \\
\text { Sintomas* }\end{array}$}} & \multirow{2}{*}{\multicolumn{2}{|c|}{$\begin{array}{l}\text { BRMV } \\
\text { Sintomas* }\end{array}$}} \\
\hline & & & & \\
\hline & Local & Sistêmico & Local & Sistêmico \\
\hline \multicolumn{5}{|l|}{ Phaseolus vulgaris: } \\
\hline 'Carioca Comum' & aus & enc, $\mathrm{m}, \mathrm{nv}, \operatorname{lnh}$ & aus & $\mathrm{m}$ \\
\hline 'Rosinha-G2' & aus & enc, $m, n v, \operatorname{lnh}$ & aus & $\mathrm{m}$ \\
\hline 'Carnaval' & aus & enc, $\mathrm{m}, \mathrm{nv}, \operatorname{lnh}$ & aus & $\mathrm{m}$ \\
\hline 'Rio Tibagi' & aus & aus & aus & $\mathrm{m}$ \\
\hline \multicolumn{5}{|l|}{ Glycine max: } \\
\hline 'Santa Rosa' & aus & $\mathrm{ma}, \mathrm{m}$ & aus & aus \\
\hline Crotalaria $\mathrm{sp}$. & aus & aus & aus & mcs, $m$ \\
\hline Chenopodium quinoa & aus & aus & $\mathrm{mcl}$ & mes \\
\hline Mucuna deeringiana & aus & aus & aus & enc, $m$ \\
\hline
\end{tabular}

aparecimento de lesões cloróticas, locais e sistêmicas em $C$. quinoa, o que também foi observado neste trabalho (Tabela 1). Costa \& Costa (1983) verificaram que o Cowpea severe mosaic virus (CPSMV), da família Comoviridae, gênero Comovirus, também pode induzir o aparecimento de lesões locais e sistêmicas em C. quinoa. A espécie Mucuna deeringiana (Bort) Merr. (mucuna anã), a qual pode ser infetada com o BRMV apresentando sintomas de mosaico, deformações severas e morte apical, em alguns casos, mostrou-se imune ao SBMV. Assim, essa espécie pode também ser utilizada para separação dos dois vírus, assim como, para separar o BRMV 


\section{M.D.G. Gasparin et al.}

do SBMV quando em infecções mistas no feijoeiro (Tabela 1). Em infecções mistas do BCMV e SBMV, espécies de Crotalaria podem servir como diferenciadoras, uma vez que estas são suscetíveis ao BCMV e imunes ao SBMV (Costa, 1987).

Com relação à sintomatologia, a maioria das cultivares de feijoeiro reagiu de maneira similar à infecção com o SBMV apresentando sintomas de mosaico sistêmico, encarquilhamento, epinastia, e redução do crescimento das plantas. Quanto à soja, algumas das cultivares testadas apresentaram manchas anelares cloróticas e mosaico leve. Estes resultados se assemelham aos encontrados por Costa \& Vega (1987), que observaram a presença de manchas anelares ou manchaschuvisco de coloração amarela em soja 'Santa Rosa'. As cultivares de soja, mesmo quando infetadas, puderam ser consideradas como tolerantes, pois as infecções sistêmicas nas folhas se tornaram menos severas com o tempo e aparentemente não comprometeram o desenvolvimento normal da planta.

Nos testes com 800 sementes obtidas de cultivares de feijoeiro e de uma cultivar de soja com sintomas, não houve transmissão para as novas plantas nas condições em que foram semeadas. Resultados semelhantes foram verificados por Bashir \& Hampton (1993), os quais não conseguiram a transmissão do SCPMV por sementes de caupi. De acordo com Cheo (1955), a ausência de transmissão por sementes pode estar relacionada ao fato de que a infetividade do vírus em embriões imaturos é inibida muito rapidamente quando sujeita à desidratação da semente no processo de maturação. Todavia, Tremaine \& Hamilton (1983) descreveram a transmissão do SBMV nas porcentagens de 1 a $5 \%$ através de sementes de feijoeiro e a transmissão do SCPMV de 5 a $40 \%$ em sementes de caupi. A transmissão por sementes também pode estar relacionada às características das estirpes do SBMV e também às cultivares utilizadas.

O seqüenciamento dos isolados do SBMV de São Paulo (Moreira \& Gaspar, 2002) e do Paraná permitirá verificar o grau de similaridade entre os dois isolados brasileiros do vírus com outros isolados já seqüenciados, e poderá contribuir para $\mathrm{o}$ entendimento das causas da variabilidade existente nas características biológicas das estirpes do SBMV.

\section{REFERÊNCIAS BIBLIOGRÁFICAS}

BASHIR, M. \& HAMPTON, R.O. Natural occurrence of five seed-borne cowpea viruses in Pakistan. Plant Disease 77:948951. 1993.
BIANCHINI, A., MARINGONI, A.C. \& CARNEIRO, S.M.T.P.G. Doenças do feijoeiro. In: Kimati, H., Amorin, L., Bergamin Filho, A., Camargo, L.E.A. \& Resende, J.A.M. (Eds.) Manual de Fitopatologia, $3^{\text {rd }}$ ed., Agronômica Ceres. 1997. pp.376-399.

CHEO, P.C. Effect of seed maturation on inhibition of Southern bean mosaic virus in bean. Phytopathology 45:17-21. 1955.

COSTA, A.S. Fitoviroses do feijoeiro no Brasil. In: Bulisani, E.A. Feijão: fatores de produção e qualidade. Campinas: Fundação Cargil. 1987. pp.173-256.

COSTA, A.F. \& COSTA, C.L. Efeito de infecções simples e duplas de quatro vírus sobre a produção e algumas características da planta de feijoeiro (Phaseolus vulgaris L.). Fitopatologia Brasileira 8:616. 1983. (Resumo)

COSTA, A.S. \& VEGA, J. Mancha-bigode em sementes de soja, associada à infecção pelo vírus do mosaico do feijoeiro do sul dos EUA. Fitopatologia Brasileira 12:145. 1987 (Resumo).

COSTA, C.L., SANTOS, O.R. \& ULHOA, S.C. Disseminação diferencial do vírus do mosaico-do-sul do feijoeiro pela população natural de besouros vetores. Fitopatologia Brasileira 12:146. 1987 (Resumo).

CUPERTINO, F.P., COSTA, C.L, LIN, M.T. \& KITAJIMA, E.W. Infecções simples e mistas dos vírus do mosaico-do-sul e do mosaicoem-desenho em feijão-vagem no Brasil central. Fitopatologia Brasileira 7:269-274. 1982.

FAO Statistical Databases. Disponível em <http://faostat.fao.org/ faostat/> Acesso em 11 de janeiro de 2005.

FARIA, J.C., ANJOS, J.R.N., COSTA, A.F., SPERÂNCIO, C.A. \& COSTA, C.L. Doenças causadas por vírus e seu controle. In: Araujo, R.S., Rava, C.A., Stone, L.F. \& Zimmermann, M.J.O. (Eds.). Cultura do feijoeiro comum no Brasil. Piracicaba: Potafos. 1996. pp.731-760.

FAUQUET, M.C. \& MAYO, M.A. Abbreviations for plant virus names - 1999. Archives of Virology 144:1249-1273. 1999.

HULL, R. The banding behaviour of the viruses of Southern bean mosaic virus group in gradients of Caesium Sulphate. Virology 79:50-57. 1977.

KITAJIMA, E.W. \& NOME, C.F. Microscopia eletrónica em virologia vegetal. In: Docampo, D.M. \& Lenardón, S.L. (Eds.) Métodos para detectar patógenos sistémicos. Córdoba, IFFIVE/ INTA-JICA. 1999. pp.59-87.

LAEMMLI, U.K. Cleavage of structura proteins during the assembly of the head of bacteriophage T4. Nature 227:680-685. 1970.

MOREIRA, A.E. \& GASPAR, J.O. Propriedades moleculares de um isolado brasileiro do Southern bean mosaic virus. Fitopatologia Brasileira 27:292-297. 2002.

TREMAINE, J.H. \& HAMILTON, R.I. Southern bean mosaic virus. CMI/AAB Descriptions of Plant Viruses, n. 274. 1983. 